\title{
Moral and Cultural Awareness in Emerging Adulthood: Preparing for Multi-Faith Workplaces
}

\author{
Patricia Snell Herzog ${ }^{1}{ }^{*}$, De Andre' T. Beadle ${ }^{1}$, Daniel E. Harris ${ }^{2}$, Tiffany E. Hood ${ }^{3}$ and \\ Sanjana Venugopal ${ }^{4}$ \\ 1 Department of Sociology \& Criminal Justice, University of Arkansas, Fayetteville, AR 72701, USA; \\ dbeadle@uark.edu \\ 2 Department of Management, Sam M. Walton College of Business, University of Arkansas, Fayetteville, \\ AR 72701, USA; dharris@walton.uark.edu \\ 3 Department of Psychological Science, University of Arkansas, Fayetteville, AR 72701, USA; \\ temiller@uark.edu \\ 4 Department of Biochemistry, University of Arkansas, Fayetteville, AR 72701, USA; svenugop@uark.edu \\ * Correspondence: herzog@uark.edu; Tel.: +1-479-575-3779
}

Academic Editor: John Bartkowski

Received: 29 January 2016; Accepted: 11 April 2016; Published: 15 April 2016

\begin{abstract}
The study evaluates a pilot course designed to respond to findings from the National Study of Youth and Religion (NSYR) and similar findings reporting changes in U.S. life course development and religious participation through an intervention based on sociological theories of morality. The purpose of the study is to investigate the impacts of a business course in a public university designed to prepare emerging adults for culturally and religiously diverse workplaces. The intended outcomes are for students to better identify their personal moral values, while also gaining cultural awareness of the moral values in six different value systems: five major world religions and secular humanism. The study response rate was 97 percent $(n=109)$. Pre- and post-test survey data analyze changes in the reports of students enrolled in the course (primary group) compared to students in similar courses but without an emphasis on morality (controls). Qualitative data include survey short answer questions, personal mission statements, and student essays describing course impacts. Quantitative and qualitative results indicate reported increases in identification of personal moral values and cultural awareness of other moral values, providing initial evidence that the course helps prepare emerging adults for multi-faith workplaces.
\end{abstract}

Keywords: religion; morality; faith traditions; emerging adulthood; generational changes

\section{Introduction}

Emerging adulthood is a relatively new stage of life that developed in response to a number of macro-structural changes in the last several decades in the United States [1]. Though many generations have had transitional periods as they discerned adulthood trajectories, emerging adults today now spend a decade or more somewhere between their adolescence and young adulthood. While emerging adulthood can be a time of personal optimism and hope for the future, it is also a period filled with disjointed processes in transitioning to adulthood, turbulence, and moral confusion as young people attempt to establish themselves. Research indicates that many emerging adults have difficulty identifying the moral values that guide their everyday behaviors and instead tend more often make decisions without considerable self-reflection $[2,3]$. This is especially a problem for workplaces, which rely upon a basis of moral values for ethical decision-making [4].

To respond to this issue, the University of Arkansas Walton College of Business, in partnership with the Tyson Center for Faith in Spirituality in the Workplace, is offering a new course entitled, 
"Authentic Leadership in a Multi-Faith Workplace: Remaining True to Yourself in a Professional Kaleidoscope." The goal of the course is to help students of all faith traditions and of no faith tradition to identify their moral values by reflecting on meaning, purpose, and core beliefs, while also learning about other religious and cultural value systems. This is primarily accomplished by exposing students to basic familiarity with the traditions of multiple world religions, represented by five wisdom traditions as well as secular humanism. Specific tasks throughout the semester are dedicated to practicing difficult conversations and writing a personal mission statement that articulates personal moral values as applied to future workplaces. The intended change of this process is to facilitate emerging adults in explicating their moral values toward developing an effective and authentic sense of self, while also learning to respect the plurality of value systems toward becoming culturally aware leaders of multi-faith workplaces.

The purpose of this study was to investigate the impact of the course on facilitating emerging adults in identifying their moral values while also gaining greater cultural awareness. While assessing impact presents a number of challenges, the current study advances knowledge on an intervention designed to respond to known trends by conducting a natural field experiment. Since a laboratory experiment risks external validity, the natural method is preferred, despite its limitations. To control for spurious effects to the extent possible, several methods were undertaken to collect data through a quasi-experimental design: a time one to time two comparison to isolate causal changes within the study duration, a treatment group compared to similar control groups without the primary intervention of interest in order to isolate self-selection effects, and implementation of nationally normed survey measures that allow for nationally representative data to be systematically analyzed for regional subpopulation differences. Despite these controls, a number of limitations remain and are described in the discussion section.

This study investigates the following research questions: Does a course designed to prepare emerging adult college students for multi-faith workplaces appear to develop greater moral and cultural awareness? Upon completion of the course, do students report that they are better able to identify their own moral values and have gained greater awareness of other value systems? Before investigating those questions, the next section summarizes the empirical and theoretical background leading to the creation of this course and to this study designed to evaluate its impacts. To our knowledge, this study is the first of its kind to move beyond description and explanation of existing trends into the relatively uncharted territory of investigating an intervention designed to alter the progression of these trends, at least for the group of participating students. As such, the study is not a replication of well-tested procedures for studying this type of course, of which there are few examples. Instead, we ground the study and its research questions in a rich theoretical and empirical background that indicate the need for this pilot course and a study of its effects. Thus, the next section does not provide a conventional literature review of studies the study parameters, as such is not yet available, and instead describes the theoretical and empirical background leading to the creation of this pilot course, its designed intervention, and this offered approach for its study.

\section{Theoretical and Empirical Background}

\subsection{Religiosity, Spirituality, and Morality in the Workplace}

A study of this kind is needed because extant scholarship highlights the importance of studying religiosity as a key aspect of workplace diversity management [5-7]. In reviews of numerous studies, a link is consistently found between religion and spirituality in the workplace and a range of organizational and individual outcomes, such as physical and mental health, creativity, organizational commitment, and ethicality [7,8]. A number of socially desirable outcomes positively associate with workplace spiritual values, including greater employee well-being, lower occupational stress, and decreased employee fatigue [9]. Business leaders who incorporate religious or spiritual practices into 
their management have lowered stress in handling challenging workplace dynamics [10] and their employees have improved job performance [11].

Of particular importance for organizations is the link to ethical decision-making [12], such that religiosity can offer employees and leaders a shared sense of business ethics [13], acting as a "managerial moral strategy", especially when moral values have been formulated in advance of an ethical decision [14]. Studies find that ethical decision-making is a process that happens through several trainable cognitive strategies that are gained through moral evaluation practice [15] and lead to greater "moral awareness" [16]. In particular, an internalized sense of moral awareness, as compared to interpersonal forms of religiosity, has significant effects on ethical decision-making [17]. This is perhaps related to findings that personal ownership is a necessity for actualizing organizational missions [18]. As such, organizational business ethics often rely upon a set of pre-formulated moral values that are often acquired through religious or spiritual participation.

However, this is a relatively new and underdeveloped area of study that offers more in identifying the importance and calls for future studies than it does in delivering empirical results [19-23]. Further studies are especially needed in this area due to findings that religiosity and spirituality in the workplace can alternatively lead to negative effects [24], such as increased discrimination and marginalization of diverse religions by the dominant workplace religion Thus, it is important to study personal moral awareness that may be based in religious or spiritual traditions while also considering cultural awareness: sensitivity to moral values based in other religious and cultural traditions. Such a dual focus is developed by considering a sociologically informed perspective on the changing role of religiosity in modernity and its resulting social differentiation of moral values [6].

\subsection{Modernity, Morality, and Religiosity}

To understand modern workplace religious and cultural diversity, it is necessary to consider insights from social theories regarding changes to modern society brought on by industrialization. Historical and contemporary sociology of religion contributes to an understanding of the societal roles of religions within their changing social contexts. Durkheim and similar theories of religion focus on the social impacts of religiosity, viewing religions as representing agreed upon norms of behaviors from a shared sense of morality that is gained from ritualistic practices and can affect social settings such as workplaces $[25,26]$. From this perspective, moral values are viewed as sets of individually internalized social values that guide decisions about right and wrong in any given situation [27-29]. Thus, moral values reflect an intersection between individual decision making and cultural value systems, as internalized societal guidelines for what is considered to be meaningful, valuable, and important to be and do. These social values guide individual behaviors.

Durkheim [30] theorized that when individuals in a non-diverse religious culture made decisions, they were mostly based on religious moral values that provided societies with a shared sense of right and wrong (mechanical solidarity). However, recent trends indicate that declining participation in religious and other voluntary organizations is likely changing the extent to which young people develop moral values within shared social and cultural contexts (organic solidarity). Based on social theory, we take this to be an indication that cultural conflicts could increase as people from diverse backgrounds encounter multi-faith workplaces and the existence of pluralistic moral values. Yet most workplaces rely upon a shared sense of moral values to undergird ethical decision-making. This raises important questions regarding the changing role of religion in society, and specifically the extent to which religious value systems still provide people with a shared sense of moral values to facilitate workplace cohesion or whether workplace frictions are likely to increase as religious heterogeneity enables greater diversity of moral values.

Additionally, sociologists investigate the changing role of religion and morality in society by examining measures of religious participation and cultural changes over time. For example, results from the National Study of Youth and Religion and other studies provide numerous findings regarding demographic and cultural shifts in religious and civic participation among American young people 
(e.g., [31-37]). Likewise, in examining changes in religious participation longitudinally within the same cohort of American adolescents as they progressed to early adulthood, we found a net decline. The dominant trend was for stability, with 22.6 percent stable in being highly religiously engaged, 16.5 percent stable in being low-moderate, and 17.4 percent low stable. For 6.9 percent of the sample, there was a tremendous increase in religious engagement over time. However, 9.5 percent evidenced steep decline, and 27.1 percent shallow decline. Combined, Figure 1 shows that this totals to the majority, 57 percent, entering emerging adulthood with the same religious participation they had when in their teenage years, and with nearly seven percent increasing. Yet 37 percent of young Americans enter emerging adulthood less engaged in religious activities than when they were teenagers. This compounds with the already accrued generational declines to reveal a net decline between generations and within the same generation.

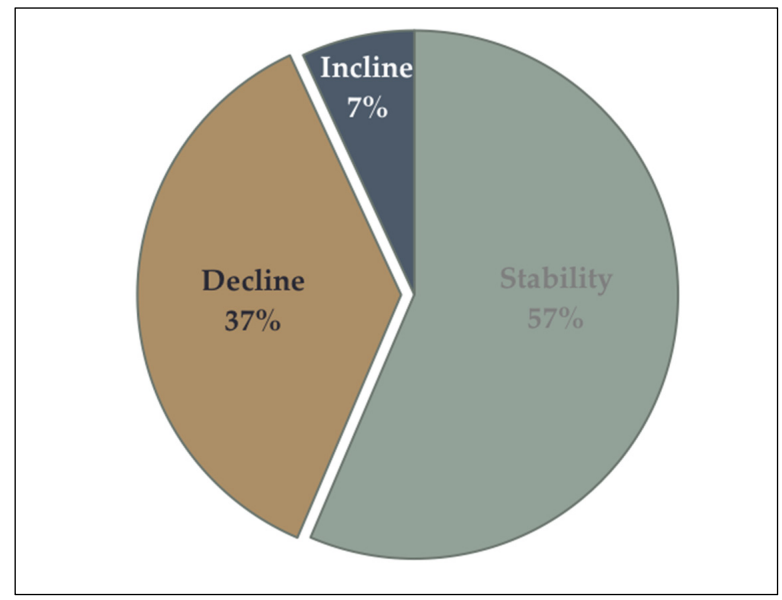

Figure 1. This figure represents the sum of longitudinal trends in religiosity as adolescents entered emerging adulthood, showing net decline. Author calculation based on findings reported in [12].

Likewise, in twenty years of General Social Survey data, Tom Smith finds that younger cohorts have consistently been less likely to vote than older cohorts [36]. However, recent young cohorts show further decline in voting rates relative to previous generations when their same age. Similarly, younger cohorts have consistently been less religious than older cohorts, but recent young cohorts have evidenced declining religiosity relative to prior generations at their same age, especially through attending religious services less often and being less likely to identify as religious. Overall, younger cohorts have the least organizational participation of any kind, have lower rates of social trust, and view other people as less helpful than did prior generations. In summary, sociology has historically identified religious traditions as a primary source for people learning moral values and constructing a shared sense of what is important to be and do, but processes of social differentiation have eroded a shared moral value system, resulting in diversity of moral values learned in different cultural contexts, and increasingly in the American religious landscape a lack of participation in religious value systems.

\subsection{Generational Changes and Emerging Adulthood}

What accounts for these monumental changes in religious and civic participation? Part of the answer lies in generational changes resulting in a new life stages that is altering the social processes of growing up and establishing adulthood. Arnett $[1,38]$ identifies a number of changes in Western culture that he argues have contributed to the development of a new life stage called "emerging adulthood." During this life stage, the individual has appeared to move beyond adolescence but has not yet reached full adult responsibility. The distinctive feature of emerging adulthood relative to previous generations is that young people today are increasingly taking longer pathways to adulthood [39-42]. 
The emerging adulthood life stage is described primarily by tremendous variability in transitioning into adult social roles [43].

As a new life stage, emerging adulthood appears to have resulted from four historical changes beginning in the 1960s and 1970s: the technology revolution, the sexual revolution, the women's movement, and the youth movement ([1], p. 3). The technology revolution refers to the advancement of machines to perform manufacturing jobs, resulting in formerly industrialized countries having "shifted from a manufacturing economy to a service economy" ([1], p. 4). The consequence of this shift to a service economy is a greater participation in postsecondary education and training, which contributes to delays in marriage and family formation [44]. Delays in marriage and family formation are also related to the sexual revolution that was facilitated by increased availability of birth control, which also coincided with decreased moral taboos surrounding sexual morality during the 1960s [1]. A third historical change that contributed to the development of the emerging adulthood life stage was the women's movement. Greater opportunities to pursue higher education and have careers, significantly altered the roles and status of women in society [45]. Arnett summarizes the fourth historical change as the youth movement, referring to the time when many youth "denigrated adulthood and exalted being, acting, and feeling young" ([1], p. 6). This movement resulted in a marked cultural shift in how young people view the responsibilities of adulthood, and a lingering desirability to stay young as long as possible. Despite these cultural changes in adulthood transitions, Settersten and Ray find that the twenties are crucial years for making investments that have long-term impacts on adulthood futures [46]. They argue that the delayed pattern is beneficial because it allows young people time to make more strategic choices, and build credentials, skills, and experiences that will ensure stronger and more stable futures.

Regardless of whether delays in life stage development are beneficial for more successful adulthood transitions or whether adulthood is resisted, the central impact of the life stage of emerging adulthood on religiosity is that the delay in adulthood transitions tends to thwart sustained participation in organizational participation of any kind. "Emerging adults are not only less religiously committed and involved than older adults but also tend to be less involved in and committed toward a wide variety of other, nonreligious social and institutional connections, associations, and activities." ([3], p. 92). Scholars find that "life-course events such as marriage, careers, and religious beliefs are "increasingly left to individuals to decide on their own, leaving people to take on new responsibilities for living with the consequences of their actions and decisions, for good and bad" ([47], p. 203; [48]). Thus, studies of emerging adulthood find a number of macro-structural changes that have led to the development of this new life stage and which have also affected religiosity and faith development over the life course.

\subsection{Moral Development}

Given these significant social changes and alterations in life course progression, how does morality develop as one cognitively and emotionally matures? One of the most notable answers to this question was Stages of Faith, in which Fowler identifies seven stages throughout the life cycle that represent a step-wise development in faith that culminates in the ability to reflect upon one's own moral values [49]. In the work of Fowler there is an understanding of moral development from a life stage perspective. Fowler purports that faith and even life is a dynamic, non-static, ongoing process of change and development. Fowler suggested that faith development as a universal human endeavor that deals with how a person believes rather than what a person believes.

Fowler saw faith development as a process with six marked stages that correspond to increased cognitive capacity. The precursor stage begins with the first two years of life, during which children understand basic concepts such as nurture versus neglect. Stage 1, "Intuitive-Projective Faith" is noted by the emergence of imagination and stimulation in response to stories and symbols, which is yet unrestrained by logical thinking. Experiences and images in this stage have long-lasting effects on the life of faith, both positive and negative. This is a stage of self-awareness, called 
epistemological egocentrism, in which perspective taking has not yet developed. As defined by Fowler, the "Mythic-Literal Faith" of the second stage happens as children become more capable of concrete operational thinking and begin to sort out real from make believe. Children at this stage are most focused on reciprocal fairness and immanent justice.

Beginning in adolescence, stage three is "Synthetic-Conventional Faith" in which social experiences most centrally expand beyond the family, with external social spheres providing sources of authority. New cognitive abilities make mutual perspective-taking possible, enable integration of diverse self-images into a coherent identity, and allow for evaluation of previously taken-for-granted ideas. Feedback from others can be influential in providing positive or negative evaluations of nascent self identities. The fourth stage is "Individuative-Reflective Faith," in which a critical reflection on beliefs, background and values occur. This is when an understanding forms of the self and others as a part of a social system. Fowler define two more stages-“Conjunctive Faith" that focuses on faith paradoxes and "Universalizing Faith" that involves an overcoming of faith paradoxes grounded in oneness with the power of being. However, Fowler reports these latter two stages to be rare, and the changes of the previous section raise questions as to their existence.

While Fowler described this influential theory of faith stages, empirical investigations of the theory have found limited and sometimes conflicting support for this stage-like, linear progression in the way faith develops over time [50]. Moreover, the social changes resulting in emerging adulthood are likely to have altered the developmental process significantly in the three decades since Fowler began studying the life course and faith development. In terms of faith development, the most notable of these is declining religious participation, which makes a singular and universal process of faith development even less likely than it may have been during Fowler's time. While a number of positive social changes have resulted from an increasingly diverse religious landscape in America, one potential issue is that it is less clear how young people are to make meaning of the myriad options available for understanding what is right and wrong to be and do. In this process of social differentiation, there is potential for greater social conflicts to exist, especially in workplaces that often bring together people who may not otherwise be in social contact, thereby increasing the changes of exposure to pluralistic moral values. Moreover, workplaces rely upon ethical decision-making that formerly was based upon moral value systems that were socialized in other social spheres, such as religious congregations. Thus, declining religious participation for younger cohorts implies that moral values are less often meaningfully made within religious contexts.

\subsection{Moral and Cultural Awareness}

Yet numerous studies find the importance of developing a sense of meaning during life course development, especially through forming a sense of identity [51-55]. Having a faith identity or moral value system relates to a host of positive emerging adult outcomes and appears to be a protective factor during life course development [56-58]. Most notable is that having a sense of personal moral values can give meaning and fill existential voids regarding life purpose, a critical psychological well-being issue. Thus, moral meaning making is an important life process, and developing moral values appears to be an important part of a healthy life course.

However, young people are less likely to enter emerging adulthood with religiously socialized moral values, raising the question: How do emerging adults today learn to identify their moral values? We do not yet know the answers to this question. The limited existing studies in this area are mostly based upon under supported theories that are becoming increasingly outmoded due to their data being collected prior to the changes resulting in the new life stage called emerging adulthood described above. Moreover, the life stage has significantly altered, with religious participation markedly declining. This means that young people in contemporary America are less likely than prior cohorts to participate in meaning-making activities within religious congregations, or within voluntary organizations of any kind. It also means that there is a lack of updated information regarding how emerging adults learn to make meaning of their social experiences by identifying their personal values, but in ways that do not 
become religiously and culturally hegemonic by respecting the pluralistic milieu of diverse religious and cultural values.

In response to this dearth of updated understandings of emerging adult moral meaning making, this study investigates the piloting of an approach within a large public university to facilitate emerging adults in developing moral reasoning skills for diverse, multi-faith workplaces [16,59-61]. The goal is to raise student moral awareness without culturally hegemony.

\section{Methodology}

This study collects data on a natural field experiment designed to test whether a college course appeared have its desired impacts. Data were collected in the Fall of 2014 via a survey distributed at the beginning, Time 1, and end of the semester, Time 2, to the primary class and to three control groups of similar leadership classes. The study response rate was 97 percent $(n=109)$. One quarter of this was the primary class, compared to three quarters in the control classes. T1-T2 pairs total 89 percent of the sample $(n=97)$. The composition of the class entailed slightly younger females than males (Figure $2 a)$. Two-thirds were business majors, and most of the non-majors were business minors. The vast majority was religious and dominantly Protestant or Catholic (Figure 2b).



(a)



(b)

Figure 2. Primary class gender, age, and major at Time 1. (a) The primary class represented a slightly greater proportion of female students compared to the control group students. Within the class there was even representation among genders, with female students being slight younger than the male students (y-axis is student counts); (b) more than two-thirds of students were Protestant or Catholic.

\subsection{National Comparison}

To assess potential regional differences in the study, questions from the National Study of Youth and Religion (NSYR) [62] were included on the survey to create benchmarks for comparison to nationally representative data. Such an approach is, to our knowledge, not existent and, therefore, we pilot an approach to using nationally normed data for this purpose. To be clear, this brings the regional location of this one locale study out of the unknown limitations into an empirically known analysis. To do this, respondents were selected from the NSYR Wave 3 survey, when NSYR respondents were the same average ages as the college students in this study. From the larger nationally representative data, a subsample was selected who lived in the South (42 percent), were enrolled in college (51 percent), and were 20 or more years of age (60 percent, sample size is 315 respondents). We then compared 
results for this group of NSYR respondents to results for the respondents in our study on the measures from the NSYR survey that were also included in this survey to allow such a comparison.

Statistical tests comparing this nationally representative subgroup to the primary and control groups at T1 find a slight overrepresentation of females: 54 percent of primary respondents $(\mathrm{n}=14)$, compared to 46 percent of NSYR respondents $(n=145)$. Religiously the classes are similar to the NSYR subgroup: classes are 69 percent Protestant $(n=18), 12$ percent Catholic $(n=3)$, zero percent Other, and 19 percent not religious or indeterminate religiosity $(n=5)$, compared to in NSYR subsample as 68 percent Protestant, 17 percent Catholic, 2 percent Other, and 14 percent not or indeterminate. The largest differences between the nationally representative subsample and classes were on self-reported importance of faith and viewing religion as a private matter. The primary class was significantly more likely to rate faith as very to extremely important, whereas the primary class was significantly less likely to agree that religion is private. Results are displayed in Table 1.

Table 1. Comparison between the primary class, control groups, and subsampled national study on the two measures with most Time 1 self-selection for the primary class.

\begin{tabular}{cc}
\hline Importance of Faith & Religion is Private \\
\hline $75 \%$-Primary $(\mathrm{n}=26)$ & $21 \%$-Primary $(\mathrm{n}=26)$ \\
$58 \%$-Controls $(\mathrm{n}=83)$ & $47 \%$-Controls $(\mathrm{n}=83)$ \\
$56 \%$-National $(\mathrm{n}=315)$ & $52 \%$-National $(\mathrm{n}=315)$ \\
\hline
\end{tabular}

The primary class evidences a self-selection for higher than average importance of faith, with 75 percent rating it very to extremely important, compared to 58 percent with the same rating among the control group classes in the same university and compared to 56 percent in the regional and comparable national subsample. At Time 1, the primary group also evidenced a lower rating for agreeing that religion is a private matter, with only 21 percent of the primary group agreeing, compared to 47 percent of within-university control groups, and 52 percent of national subsample.

\subsection{Control Comparison}

In addition to the site-specific differences between the classes studied and the nationally representative subsample, there are also some differences between the primary class and control classes. Students in the primary class were statistically significantly more likely than the control groups to disagree at Time 1 that lying is sometimes alright if it is profitable, 76 percent of primary respondents $(n=20)$ compared to 44 percent of control group respondents $(n=37)$. Combined with the national differences, there is some evidence of a self-selection effect of emerging adults with statistically significant differences between the control groups and the treatment group, who reported higher importance of faith, greater belief that religion is a public matter, and with more propensities to infuse their morals in the workplace by adhering to their ethical principles even when it comes at a shorter-term personal or organizational cost. Despite these differences, the data of this study present an opportunity to study an intervention effort designed to facilitate emerging adults in becoming more aware of, culturally sensitive to, and better articulators of their moral values and personal missions, especially among those already primed for moral engagement and among a group of relatively committed emerging adults. As such, this course provides a relatively stringent case study for a pilot course among a group of emerging adults known to be particularly non-representative of the average American emerging adult and, therefore, expected to show minimal or no change in their moral and cultural awareness due to their high initial religiosity.

\section{Results}

The results of the study indicate statistically significant changes over time in student Time 1 to Time 2 quantitative reports of their levels of moral and cultural awareness (as compared to 
control groups), which they qualitatively attribute to aspects of the intervention course. The largest quantitative changes between Time 1 and Time 2 were in cultural awareness, with the primary class having a statistically significant mean increase of 0.89 as compared to the control groups.

There was also a mean increase of 0.37 in the primary class in their confidence managing conflicts. The primary class also agreed more at Time 2 that they viewed the religion of their youth positively, with a 0.46 mean increase. Thus, primary students most notably gained in their cultural awareness, understanding, and identification of their moral values, positive feelings toward the religion of their youth, and confidence in managing workplace conflicts.

\subsection{Control Group Changes}

In terms of the qualitative findings, students in the control groups did not evidence significant changes in their open-ended responses regarding their life purpose. For example, one control group student who was unsure of his or her life purpose at Time 1 reported: "I don't really know my purpose in life just yet. But am confident I'll figure it out eventually." At Time 2, this same student responded simply, "I don't know yet." Another student in the control group said this at Time 1, "I believe that I was created by God for the purpose of glorifying him. My beliefs in and about God and myself define my meaning and purpose of everything I do or am." This same student at Time 2 said, "I believe God created me firstly to glorify him in how I respond to the world and its challenges, and to also honor him by loving other people in his name. I am created to be loved by him, and to love him back." A third example comes from a non-religious student who said at Time 1, "Although I feel that life always present[s] uncertainties and questions that cannot be answered, I have a strong sense of my strengths and aspirations." At Time 2, this same student said "I feel like it is my responsibility to be fair and kind to others while bettering myself and striving for success." These form the baseline qualitative comparisons for the following primary class qualitative results.

\subsection{Personal Mission Statements}

The culminating assignment of the course was the students writing a personal mission statement that they submitted three times through the semester, with revisions based on instructor feedback on prior drafts. This serves as the primary change mechanism, providing students with reflection on all the course content as it relates to them personally. For example, one student wrote:

[My mission is] being an authentic, genuine and reliable leader that others can admire, look up to and aspire to be. Establish and create a work environment that is welcoming and accepting of all people who come from different backgrounds, experiences and walks of life. Challenge myself to seek opportunities to try or learn something new as often as possible. Vow to surround myself with individuals different from myself, ask questions and search for answers in order to cultivate growth.

Another example of a personal mission statement, and one that evidences a connection between pre-defined moral values and potential changes to ethical decision-making, is:

To choose the ethical approach by making a personal commitment to honesty and integrity. To find opportunities to use my natural talents such as patience, self-control, sincerity, and logic through my job as a CPA. To strive to be worthy of the respect and admiration of family, friends, and business associates. To find happiness, fulfillment, and value in living.

While the data for this study are collected while students are still in college, the personal mission statements written by students often evidenced the potential for the preparations of this course to impact the kind of work they will do once employed, especially by this student about to graduate:

I will be a positive force in the lives of others by taking time to get to know those who cross my path and helping them in any way that I can. I will not ask anything of anyone 
that I am not willing to do myself. I have an opportunity to apply these principles in the managerial position I am starting at the end of this month. One of my goals is to advance in my career so that I can touch the lives of as many people as possible. Another goal is to continuously improve myself, and to help others improve themselves.

Many students explicitly religious based moral values in their personal statements, as exampled:

I want my life, as seen by others and my creator, to exemplify the servant leadership, joy, and grace that Jesus showed the world.

In other cases, students who expressed having high levels of religiosity in their survey did not write their personal mission statements in ways that were explicitly religious, as evidenced here:

Honesty—being truthful with others but most importantly myself. Healthy—keeping a healthy mind and body is very important. Humble-having respect for others and never seeing myself as boastful. Transparency—staying open and honest with myself and others Self-knowledge-strive to know who I truly am. PMS: I will strive to create my own path to happiness, not follow others' paths, while surrounding myself with people who sharpen me into a stronger more sophisticated individual, and to one day leave a legacy for my family and children.

These quotes from end of semester personal missions statements exemplify the kind of response that students provided after participating in the course. They evidence moral awareness in personal, especially as compared to the lack of changes in the control group open-ended responses from students also in classes with in-depth discussions and revisions of written work who did not have practice articulating their personal mission statements. These qualitative results mirror quantitative results in Figure 3, providing descriptions of changes that treatment group students reported in their moral awareness and which are not reflected by control group responses.

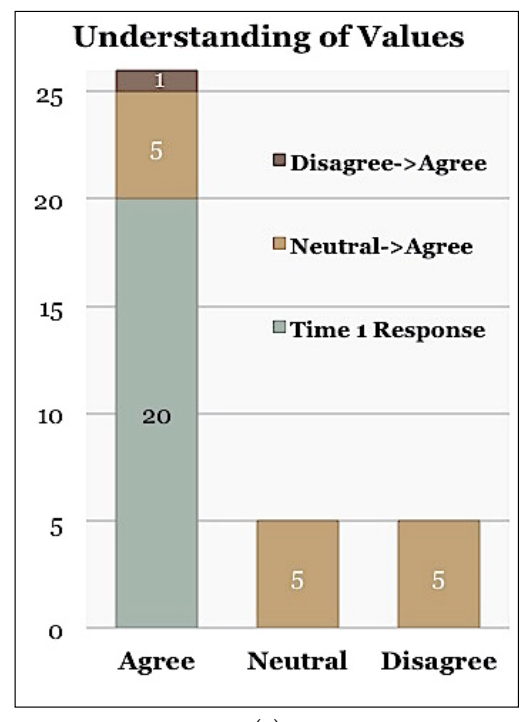

(a)

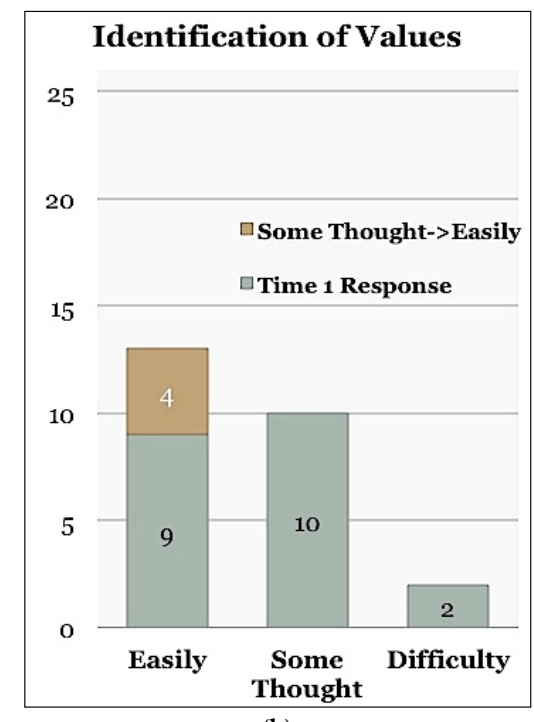

(b)

Figure 3. Primary class changes between Time 1 and Time 2. (a) Emerging adults in the primary class changed from two-thirds agreeing that they understood their values to all agreeing with this. Twenty percent $(n=5)$ moved from formerly neutral on this question to agreeing, and four percent $(n=1)$ changed from disagreeing to agreeing; (b) at Time 1, one-third of the class said they could identify their values easily $(n=9)$, and 16 percent $(n=4)$ said they could do it with some thought at Time 1 said at Time 2 that they could identify their values easily. The remaining half remained stable in their responses, with 40 percent with some thought $(n=10)$, and 8 percent with difficulty $(n=2)$. 


\subsection{Student Descriptions of Course Impacts}

In addition to personal mission statements, students also submitted final essays. In their final course essay, students were asked to describe what, if any, changes this course had on them. Many students expressed that the course helped them gain greater self-awareness, as exemplified by this:

This class helped me grow as a person. One of the reasons I took this class was to learn about other religions and how to interact with them, be more accepting, and be able to understand where they are coming from.

Additionally exemplified in the above quote, is a recurrent theme of students reporting learning about other religions with which they had minimal or no prior exposure. For example, on student stated:

I was very interested in the idea of learning more about the world religions and how they hold power over the hearts and minds of so many people. In doing so I had hoped to strengthen my own beliefs as well. I feel as though I have accomplished both of these initiatives. Learning from the many speakers we have had has been incredibly insightful. The Buddhist monk was especially interesting to me. His illustration of Logic and reason as a sort of salvation from the world was incredible. While I disagree with him in this it was an amazing experience to hear from him about his beliefs. I wish that I had more time to talk with him, but I am grateful for the time he provided to us.

Some students explicitly tied these increases in cultural awareness of diverse religions to gains in workplace skills. This student, for instance, describes a new ability for teamwork:

For strictly religious individuals without this concept, it is difficult to respect others who do not share similar beliefs because these people do not understand that values can be similar for people with different beliefs. I had this problem coming into this class. With this thought, a multi-faith team would rarely accomplish anything. Their conversations would continuous revolve around beliefs that are much less likely to change as opposed to values. Understanding this concept will assist me as an authentic leader with diverse teams.

In describing what particular aspects of the course facilitated changes in their moral awareness, students often described improvements from the process of writing and reflection, such as this:

The journal posts, especially about the different religions really helped me to write my thoughts down as well as teach me about other religions. I found that I agreed with a lot of the teachings of other religions. I think that Huston Smith's chapter about Hinduism had the biggest impact on me, as well as on my mission. I liked that the Hindu religion taught people to do what they desired and that everything anyone gets is well deserved. I have always believed that what goes around comes around, and this "motto" if you will, helped me to develop my first draft of my mission. I always have and always will want to help others. I want to make the best impression I can on each person I meet and always respect others.

Increases in cultural awareness were alternatively linked to guest speakers from diverse religions:

Another big part of our class this semester were the guest speakers, and honestly at first I wasn't sure what to expect from these times, but I found myself very enthralled by what they had to say and was propelled with that knowledge...Being familiar with other religions is a great tool to have, to be well rounded instead of ignorant.

Some students described how these increases in cultural awareness improved their emotive skills:

Hearing about the views and beliefs of people who were raised in different cultures opened my eyes. The two Buddhist speakers relayed the importance of happiness in life and the 
potential rewards for having control over our thoughts. Differentiating between feeling angry and admiring feelings of anger rising can make all of the difference in our lives. If I can start to notice when anger or sadness is rising within me, then I can faster take control of those feelings so that I will not be as affected by them.

Others described gains in the cognitive, logical processing skills from the moral awareness efforts:

The lectures helped to define and differentiate between faith, religion and spirituality. In my mind I had always assumed that these ideals were relatively all the same and could be used interchangeably. I had never grasped the true meaning behind these words and what they stood for. Through the lectures I was better able to recognize the differences and understand how I apply each of them to my life. I used to attribute faith to a theistic belief, but I have learned that it is our "overarching, integrating and grounding trust in a center of value and power which enables us to find coherence and meaning."

Relating the different course tasks to each other was described by some students as providing deeper impact through applying the learning into expressed practices. For example:

While practicing difficult conversations, I discovered that having a personal mission statement will really help me in business practice. With these tricky situations, if someone had asked why I believe what I do, I would have never been able to definitively explain. Now, because I have a mission statement, I know how to articulate my values and express why I believe one way or another. The mission statement will help me not only in dealing with difficult conversations, but in my business career as a whole.

In summary, many students described the kind of in-depth changes this course was designed to create, and quite a few were able to explicitly link the content of the course to the kind of workplace leader they want to be after completing the course and graduating. As one student eloquently said:

I will be a more effective leader in a multi-faith workplace when I understand more of my coworkers' culture: it shows that I care about them, and it keeps me from unintentionally offending someone. The speakers were not just supplemental to the reading; they were necessary to my understanding of the different wisdom traditions. The book gave me a good basis, but the speakers allowed me to understand the religion from a personal view and gave me a comfortable place to ask honest questions.

As these quotes evidence, one of the aspects of the course that had the greatest impact was exposure to multiple faiths via speakers who were devout in each of the five wisdom traditions and an ethical secular humanist speaking about how their faith affects them and their workplace behaviors. In response, emerging adults in the class evidence learning more about their own moral values and about the values of other cultures. In-depth reading of essays and personal mission statements reveals that changes need to be understood in reference to different starting positions.

\subsection{Understanding Changes Relative to Different Starting Points}

The central goal of the primary class was to facilitate emerging adult students in developing moral and cultural awareness. With the sensitizing concepts of moral and cultural awareness, Figure 4 represents a two-dimensional analytical framework that depicts a simplified version of the possible outcomes from combining these two dimensions: low to high moral awareness with low to high cultural awareness. For analytical clarity, each spectrum is represented dichotomously. 


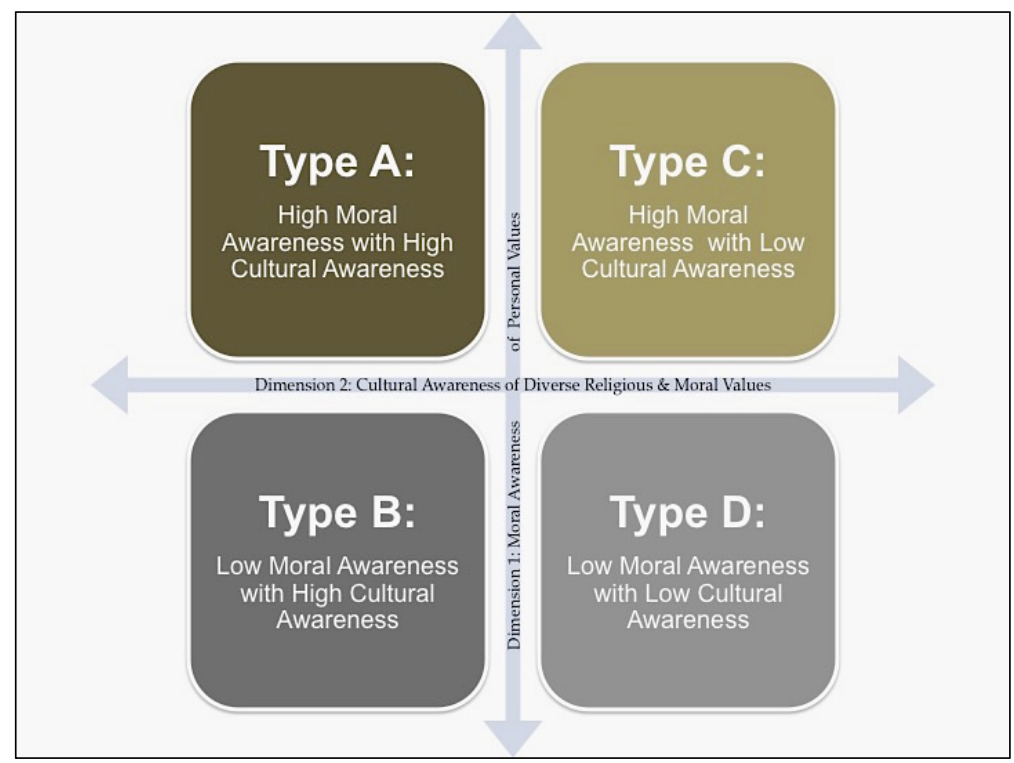

Figure 4. Two-Dimensional Framework of Written Work In-Depth Analysis. Dimension 1: Moral awareness ranging from high (top) to low (bottom) with Dimension 2: Cultural awareness ranging from high recognition of diverse religious and moral values (left) to low cultural awareness (right).

Together these dimensions form four ideal types with quadrants of: Type A-High Moral Awareness and High Cultural Awareness (upper left), Type B-Low Moral Awareness and High Cultural Awareness (lower left), Type C-High Moral Awareness and Low Cultural Awareness (upper right), Type D-Low Moral Awareness and Low Cultural Awareness (lower right).

Employing this typology, student written assignments were coded for ranges from low to high for each of the two dimensions, and students were then given a type coding based on the overall combination and prevalence of each dimension in their written works. In total there were 150 quotes coded for evidence of a relatively high moral awareness, and 69 quotations coded as evidencing low moral awareness. An example of evidence for high moral awareness is: "I will strive to have these values and goals embedded in every aspect of my everyday...I have found my values in my faith, and have designed my goals to come from my values." Another example of high moral awareness is: "I believe in ethics. I believe there are things that are just plain wrong and just plain right, from an ethical standpoint." An example of low moral awareness is: "I make my wagers based on how I feel about my decisions afterwards. I have my own moral compass, and I don't feel that I have to answer to anyone but myself at the end of the day." Another example of low moral awareness is: "There are so many gray areas in ethics, which makes determining what is ethical and what is not difficult." A third example of low moral awareness is: "I am the type of person that accepts the world as it is and goes through life being happy."

Despite cultural awareness evidencing the largest quantitative increase in survey responses, the qualitative instances were sparse, perhaps because the assignments did not directly ask for topics on this. There were 39 instances of high or increasing cultural awareness and 42 quotes of low or absent cultural awareness. An example of cultural awareness is: "In this class I have been able to respect other world religions and the ideas of others more." Another example of gaining cultural awareness is: "Up until this point, I have been naïve and uneducated about the other wisdom traditions that I myself did not identify with...What I have found is that one of the most exciting things for me is learning from people who are different from me." An example of a quote that was lacking a clear impact in increased cultural awareness is: "I knew this class was different than others that I was attending, it was more about learning what you want out of life and...that people have different ways of doing the same things." 
Combined, these evidence the presence or absence of each of the two dimensions provided the means for assigning each student a summary code representing their placement within the four quadrants depicted in Figure 4. The result of these codes are displayed in Figure 5, showing that the majority of emerging adults enrolled in this course were Type A, evidencing high moral and high cultural awareness. The next majority was Type $\mathrm{C}$-having high moral awareness but low cultural awareness, followed by Type D-low moral and low cultural awareness. The smallest proportion was Type B-evidencing high cultural awareness with low moral awareness.

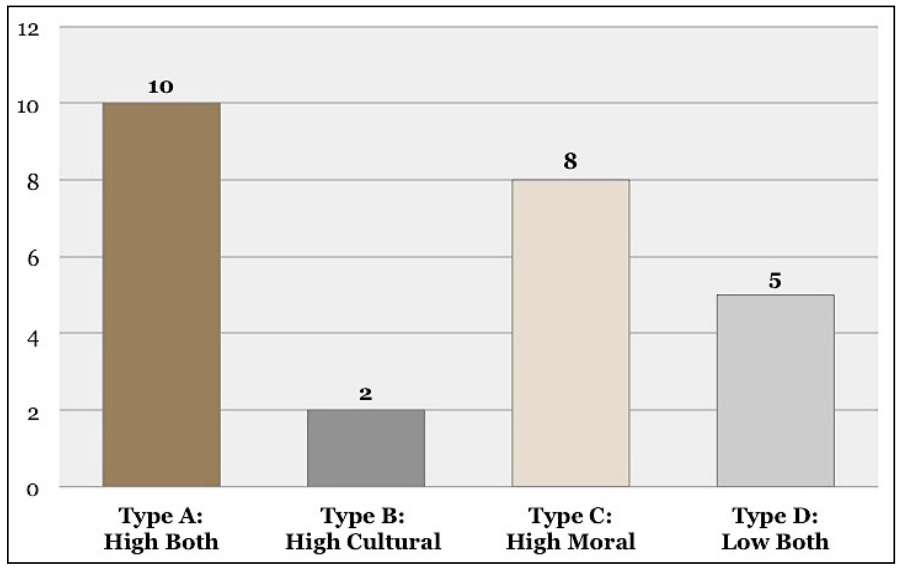

Figure 5. Typology Distribution for 2-Dimensional Framework.

These qualitative findings highlight the importance of understanding change relative to different starting points. For those already articulate about their moral frameworks, the greatest potential for change they experienced in the course is a raising of their cultural awareness. For example, one Type A student reported:

I've been a Christian for many years, and hearing about other faiths brought me closer to God. I've known about other religions, but they were presented to me as "those people are wrong, but if we know what they believe then we can more easily convert them." This instilled in me an unconscious prejudice towards anyone who follows a different wisdom tradition than I do, and in order to be truly genuine, I've had to overcome that.

In contrast, a student with a similar level of personal moral awareness but with a remaining low level of cultural awareness at the end of the semester-a Type C student-reported:

As a Christian, a very big part of my life is sharing the truth of Jesus. With that being said, an understanding of what people of other religions believe is a necessary tool if I hope to ever lead anyone to Christ who practices another religion. Being familiar with other religions is a great tool to have.

While these students evidenced a quantitatively similar high level moral awareness, the differences in their cultural awareness made them interpret the meaning of their moral awareness in distinct ways: the Type A student toward respecting different moral values and the Type $C$ toward better conversion to a homogenous set of moral values.

For those generally more culturally aware, the greatest potential for change was becoming clearer about their personal moral values. For example, one Type A student who already reported a high level of cultural awareness described their increase in moral awareness in this way:

I never really understood the true significance of writing down your values on paper. [Now I see that] it enables me to reflect on what is truly important to me and my life and concretize these values to make them meaningful and representative of who I am. I learned 
more about myself than I ever thought I could in such a short amount of time. It has been a satisfying and fulfilling experience that I will take with me through my journey in life.

Alternatively, a Type B student who reported increasing in cultural awareness but did not evidence increases in moral awareness described this somewhat confusing personal mission statement:

Our set of core values are being respectful, being honestly, being open minded, and being motivated. Being respectful is going to be the main solution to the toxic environment that exist within the team. If each team member has a sense of respect for each other and is able to step back and put their emotions aside to possibly compromise with others then there will be a better atmosphere for everyone to work. Personally being respectful is one of the most important values to have when leading or working with a group because if you do not respect others, then others will not have respect for you.

This quote helps highlight the category of student who has high cultural awareness with low moral awareness, resulting in a desire to have a great deal of respect for different perspectives but seemingly lacking any sort of "moral yardstick" by which to evaluate conflicting views. The implication is that this sort of student would take the path of least resistance in a workplace setting, which is likely to be non-desirable for organizations seeking high levels of moral engagement. Nevertheless, the increase in cultural awareness evidences improvement relative to a student showing low levels of moral and cultural awareness, such as this example:

Since I came to the first class this semester I knew this class was different than the other ones I was attending, it was more about learning what you want out of life, ways to help you achieve it, and that we as humans all undergo this same process and we need to be respectful towards others and understanding that people have different ways of doing the same things.

This Type D student evidences a minor increase in moral and cultural awareness that may represent a greater level of cultural sensitivity and awareness of possible moral clarity to what existed prior, and which is what the student reported. However, the end result by the conclusion of the course shows a qualitatively distinct meaning that the moral and cultural awareness changes reported for the other types of students, and it remains unclear what if any impact will be had on the ethical decision-making of this student when in their future workplace.

These qualitative examples help elucidate that the quantitative data is useful for describing the average trends in course impacts, especially in order to assess their magnitude as compared to control groups who necessarily did not have these assignments that are part of the intended course change mechanism. However, they also reveal that changes appearing to result from the course need to be understood relative to diverse combination of moral and cultural awareness. In summary, this study provides initial evidence that a pilot college-based course in a business school aids even highly religiously committed emerging adults in gaining greater moral and cultural awareness. As such, this approach offers one way that non-familial adults can support emerging adults in developing moral awareness for ethical decision-making while also gaining cultural awareness of the diversity of religious and other moral values, providing a non-hegemonic intervention in moral development for non-religious social settings, such as public universities.

\section{Discussion}

Recent studies have found changes occurring in life stage development and in religious participation rates within the U.S. These findings necessarily alter prior theories regarding faith and spiritual development toward moral meaning-making, which have also not been empirically well supported. This study contributes to an updated understanding of moral meaning making, and the contributions of non-familial adults in supporting emerging adults to identify and better articulate their moral frameworks. Ethical decision-making in diverse and multi-faith workplaces rely upon 
individuals with well-formulated senses of right and wrong that remain culturally inclusive. The results of this study indicate that one possible approach is for public universities to educate students about different orientations for making meaning of ethical actions.

The course intervention appeared to be best at exposing morally inclined students to the existence of other cultural and religious values, helping them to understand their own moral frameworks within a broader cultural milieu. While religious and non-religious students were found in both categories: high and low moral awareness, students who had been exposed to a religious faith but were not currently giving morality conscious attention, either as religious or as being explicitly not religious (e.g., atheist or agnostic), were less likely to have high levels of moral awareness. Rather than inculcating them with specific religious doctrine, this course offers an alternative approach to facilitating students in gaining moral and cultural awareness through exposure to diverse moral value systems, personal reflection, and application to social practices.

One of the primary contributions of the study is the analytical framework specifying distinct combinations of moral and cultural awareness. Its application to the empirical data revealed that quantitative changes in each measure individually do not necessarily represent the same qualitative impact. In other words, a change score of one can represent qualitatively distinct kinds of changes and may not actually represent a shared intensity of change across measures and students. This is because the qualitative findings identify an important intersection between the survey measures, whereby change over time means something qualitatively different for a student entering the course with a high level of moral awareness and low level of cultural awareness than for a student with a moderate level on both or the inverse intersection.

For example, Student 1 had a high level of moral awareness with a low level of cultural awareness (Type C) and described gaining from the course exposure to one specific religious tradition-Islam - which they had low prior exposure to than other religious traditions-e.g., evangelical Protestantism, Catholicism. Their moral values were shaped by evangelical Protestantism, and they had previously understood their values to be superior to those of other religions. However, the course facilitated a personal experience with a devoted Muslim that created a deeper respect for the moral values of that religious tradition, in part from recognizing the similarities to their own moral values and in part from recognizing their differences as understandable given the tenets of the faith tradition from which they were derived. As a result, Student 1 reports no changes over time in their moral awareness and a one-point change in their cultural awareness. Having had prior exposure to some religious traditions, this student does not report a large degree of change as that of a student having global lack of exposure to different religious traditions (Type D) reports, but instead reports a more modest quantitative change referring to knowledge gained on one specific religion that moves toward becoming a Type A.

Alternatively, Student 2 had a low level of moral awareness with a low level of cultural awareness (Type D) and reported a large increase in their cultural awareness with no change in moral awareness. By the end of the course, it is unclear whether they have a pre-defined moral strategy on which to gauge workplace ethical decisions. However, they report a large gain in their cultural awareness and describe that prior to this course they had not had personal experiences with people from different religions. They tended to think morals were self-evident and therefore had not put a great deal of thought into their own moral values. The student describes gaining from the course a realization that different religious traditions support some similar and some distinct moral values, causing the student to think they should do some more reflection to figure out their own sense of morality. While there is no quantitative change detected in the moral values, there is an implication in the qualitative data that this student may eventually gain greater moral awareness, having now gained the cultural awareness to become confused, a therefore think further reflection is needed to gain clarity, making the formerly implicit more explicit.

What these two example students elucidate is that changes relative to only one of the two qualities would miss important changes in the other, and moreover a great deal would be missed by not 
understanding the intersection of the dimensions and their resulting meanings. This reveals that a one-point change in cultural awareness does not mean a lower impact is had than for a student who reports a three-point change. For example, a one-point change for Student 1 could result in less ethnocentrism, while a three-point change for Student 2 could result in greater introspection. Both are important course impacts, and thus the mixed-methods design of this study was needed to uncover the true sorts of change impacts possible with this intervention approach.

\subsection{Limitations}

Despite the study strengths in offering an investigation into an updated understanding of moral development that accounts for changing trends in the life course and in declining religious participation, there are two major sets of limitations to this pilot study: its generalizability and external validity. The first set of limitations concerns the generalizability, which is hindered by the small sample size. Moreover, the design of this study allowed for the empirical investigation of potential regional skews, and the sample is found to have greater than average levels of religiosity than nationally representative data on emerging adults. Likewise, the quasi-experimental design allows for a control group comparison, and the course is found to have self-selection biases as represented by higher levels of religiosity in the treatment group at the start of the course (T1).

While these skews represent limitations to the generalizability of the data, they are a strength of the study methodology. Nationally representative studies are costly, resulting in many local studies with smaller sample sizes. However, typically these small sample studies do not include ways of empirically analyzing their potential regional skews. Thus, part of what this study offers is a way to assess and report these skews by asking nationally normed questions and comparing the sampled group results. While it is possible for unknown self-selection or regional biases to remain, these known differences were controlled to the extent possible by assessing the statistical significance of small-sample tests comparing the Time 1 and Time 1-to-Time 2 changes of the three control group classes with the same data in the treatment group. This effectively controls for known self-section biases. The highly religious skew found through these analyses indicates that this pilot study offers an especially stringent design on a group that would be expected to evidence less change in moral and cultural awareness than the average emerging adult. Thus, we think that the results presented here conservatively estimate the extent to which a course such as this can facilitate moral and cultural awareness in a more general population of emerging adults.

A second set of limitations concern the external validity of the study. For one, there is a relatively short duration between Time 1 and Time 2, without data on the extent to which reported changes will last for longer periods of time and especially after students' transition to workplaces. Second, the study findings rely upon self-reported data, both in quantitative survey measures and in written descriptions of course impacts. As such, all findings are dependent upon student truthfulness and self-awareness. At the same time, the fact that many students reported having low levels of the intended outcomes of the course indicates that students were not inclined to only give socially desirable answers, and the unique study design provides a way to learn from low self-awareness evidenced in qualitative responses. Additionally, observer evaluations of student moral and cultural awareness could be even more limited than relying on self reports.

With these limitations in mind, we offer this pilot study as a way to assess course impact within the bounds of a single semester and to assess the regionally-specific and self-selection skews inherent in any non-nationally representative study conducted at a single or multiple universities.

\subsection{Future Studies}

This pilot study provides initial evidence of the success of this course in creating short-term changes in the intended outcomes. Rather than assuming the course is successful, drawing upon anecdotal evidence, or relying upon student evaluations that mostly assess course enjoyment, this study systematically investigates student changes using multiple methods that intentionally limit and 
reasonably control for self-selection biases and regional skews. Given the initial evidence of this study, we suggest that future studies implement a similar design that draws upon nationally normed data, compares treatment results to comparable controls groups, and assesses change using quantitative survey measures, written work, and qualitative descriptions of change impacts. If the same design were implemented at multiple universities, the results could be tallied across locales into a highly affordable study with greater generalizability.

Moreover, the results of this study provide an analytical framework with initial qualitative support of its usefulness in understanding student changes. We suggest that future studies also apply this framework to quantitative data by plotting students into the categories at Time 1 and then assessing their changes over time relative to the distinct positions learned about in this study. To do so would require a larger sample size in order to have large enough groups of students in each category at the start of the study to representatively asses their multiple forms of changes. This study provides initial evidence that such an approach would be worthwhile to conduct.

This pilot study also provides evidence for the utility of studies that considerably upscale this study: by collecting data outside the bounds of a course and on nationally representative samples, tracking students over time, adding observer collected data, and linking workplace behaviors to earlier preparation strategies. Given the clear increases in both moral and cultural awareness evidenced in this modest study, we believe all such efforts would be efficacious and likely yield even more marked results than those found in this pilot study.

Acknowledgments: The authors are grateful to the University of Arkansas Tyson Center for Faith and Spirituality in the Workplace and Department of Sociology and Criminal Justice for funding student research assistance, as well as to the National Study of Youth and Religion for use of selected survey questions and comparison data. We also wish to thank Andre Delbecq for insights on the project at various stages.

Author Contributions: Patricia Snell Herzog in the Department of Sociology and Criminal Justice, primarily authored this paper, designed and programmed the survey, developed the theoretical framework, conducted the quantitative analyses, and supervised student research assistants in qualitative coding and literature reviewing. De Andre' T. Beadle in the Department of Sociology and Criminal Justice, wrote first drafts of portions of the literature review and conducted the qualitative coding. Daniel E. Harris in the Department of Management in the Sam M. Walton College of Business, designed the primary course in the study, recruited instructors for the control group courses, taught the primary class, and collected and provided feedback on personal mission statements and final course essays. Tiffany E. Hood, undergraduate student in the Department of Psychological Sciences, conducted portions of the qualitative coding and gathered relevant studies for the literature review. Sanjana Venugopal in the Department of Biochemistry, conducted portions of the qualitative coding.

Conflicts of Interest: The authors declare no conflict of interest.

\section{Abbreviations:}

NSYR National Study of Youth and Religion

\section{References}

1. Arnett, Jeffrey J. Emerging Adulthood: The Winding Road from the Late Teens through the Twenties, 2nd ed. New York: Oxford University Press, 2015.

2. Arum, Richard, and Josipa Roksa. Aspiring Adults Adrift: Tentative Transitions of College Graduates. Chicago: University of Chicago Press, 2014.

3. Smith, Christian, and Patricia Snell. Souls in Transition: The Religious and Spiritual Lives of Emerging Adults. New York: Oxford University Press, 2009.

4. Moore, Celia. "Moral Disengagement in Processes of Organizational Corruption." Journal of Business Ethics 80 (2008): 129-39. [CrossRef]

5. Duffy, Ryan D., Laura Reid, and Bryan J. Dik. "Spirituality, Religion, and Career Development: Implications for the Workplace." Journal of Management, Spirituality and Religion 7 (2010): 209-21. [CrossRef]

6. Schaeffer, Charles B., and Jacqueline S. Mattis. "Diversity, Religiosity, and Spirituality in the Workplace." Journal of Management, Spirituality E Religion 9 (2012): 317-33. [CrossRef]

7. Day, Nancy E. "Religion in the Workplace: Correlates and Consequences of Individual Behavior." Journal of Management, Spirituality \& Religion 2 (2005): 104-35. [CrossRef] 
8. Benefiel, Margaret, Louis W. Fry, and David Geigle. "Spirituality and Religion in the Workplace: History, Theory, and Research." Psychology of Religion and Spirituality 6 (2014): 175-87. [CrossRef]

9. Arnetz, Bengt B., Matthew Ventimiglia, Pamela Beech, Valerie DeMarinis, Johan Lökk, and Judith E. Arnetz. "Spiritual Values and Practices in the Workplace and Employee Stress and Mental Well-Being." Journal of Management, Spirituality \& Religion 10 (2013): 271-81. [CrossRef]

10. Delbecq, André L. "The Impact of Meditation Practices in the Daily Life of Silicon Valley Leaders." In Contemplative Practices in Action: Spirituality, Meditation, and Health. Goleta: ABC-CLIO, 2010, pp. 183-204.

11. Vandenberghe, Christian. "Workplace Spirituality and Organizational Commitment: An Integrative Model." Journal of Management, Spirituality E Religion 8 (2011): 211-32. [CrossRef]

12. Fernando, Mario, and Brad Jackson. "The Influence of Religion-Based Workplace Spirituality on Business Leaders' Decision-Making: An Inter-Faith Study." 2006. Available online: http:/ /ro.uow.edu.au/commpa pers /165 (accessed on 10 October 2015).

13. Vitell, Scott J. "The Role of Religiosity in Business and Consumer Ethics: A Review of the Literature." Journal of Business Ethics 90 (2009): 155-67. [CrossRef]

14. Soule, Edward. "Managerial Moral Strategies-In Search of a Few Good Principles." Academy of Management Review 27 (2002): 114-24.

15. Thiel, Chase E., Zhanna Bagdasarov, Lauren Harkrider, James F. Johnson, and Michael D. Mumford. "Leader Ethical Decision-Making in Organizations: Strategies for Sensemaking." Journal of Business Ethics 107 (2012): 49-64. [CrossRef]

16. VanSandt, Craig V., Jon M. Shepard, and Stephen M. Zappe. "An Examination of the Relationship between Ethical Work Climate and Moral Awareness." Journal of Business Ethics 68 (2006): 409-32. [CrossRef]

17. Kum-Lung, Choe, and Lau Teck-Chai. "Attitude towards Business Ethics: Examining the Influence of Religiosity, Gender and Education Levels.” International Journal of Marketing Studies 2 (2010): 225-32. [CrossRef]

18. Darbi, William Phanuel Kofi. "Of Mission and Vision Statements and Their Potential Impact on Employee Behaviour and Attitudes: The Case of A Public But Profit-Oriented Tertiary Institution." International Journal of Business and Social Science 3 (2012): 95-109.

19. Bandsuch, Mark R., and Gerald F. Cavanagh. "Integrating Spirituality into the Workplace: Theory \& Practice." Journal of Management, Spirituality and Religion 2 (2005): 221-54.

20. Bowman, Timothy James. "An Ideal Type of Spiritually Informed Organizations: A Sociological Model." Journal of Management, Spirituality and Religion 5 (2008): 293-320. [CrossRef]

21. Brotheridge, Céleste M., and Raymond T. Lee. “Hands to Work, Heart to God: Religiosity and Organizational Behavior." Journal of Management, Spirituality and Religion 4 (2007): 287-309. [CrossRef]

22. Probst, Tahira M., and Paul Strand. "Perceiving and Responding to Job Insecurity: A Workplace Spirituality Perspective." Journal of Management, Spirituality and Religion 7 (2010): 135-56. [CrossRef]

23. Saks, Alan M. "Workplace Spirituality and Employee Engagement." Journal of Management, Spirituality and Religion 8 (2011): 317-40. [CrossRef]

24. Chaston, Jacqui, and Marjolein Lips-Wiersma. "When Spirituality Meets Hierarchy: Leader Spirituality as a Double-Edged Sword." Journal of Management, Spirituality and Religion 12 (2015): 111-28. [CrossRef]

25. Groen, Janet. "Spirituality within a Religious Workplace: Is it So Different?" Journal of Management, Sprirituality, and Religion 4 (2007): 310-25. [CrossRef]

26. Robertson, Roland. "Individualism, Societalism, Worldliness Universalism: Thematizing Theoretical." Sociology of Religion 38 (1977): 281-308.

27. Seidman, Steven. "Modernity and the Problem of Meaning: The Durkheimian Tradition." Sociology of Religion 46 (1985): 109-30. [CrossRef]

28. Schafer, Markus H. "Ambiguity, Religion, and Relational Context: Competing Influences on Moral Attitudes?" Sociological Perspectives 54 (2011): 59-81. [CrossRef]

29. Husted, Bryan W., and David B. Allen. "Toward a Model of Cross-Cultural Business Ethics: The Impact of Individualism and Collectivism on the Ethical Decision-Making Process." Journal of Business Ethics 82 (2008): 293-305. [CrossRef]

30. Durkheim, Emile, and Karen Fields, trans. The Elementary Forms of Religious Life. New York: Free Press, 1995.

31. Pearce, Lisa D., and Melinda Lundquist Denton. A Faith of Their Own: Stability and Change in the Religiosity of America's Adolescents. New York: Oxford University Press, 2011. 
32. Smith, Christian, Kari Christoffersen, Hilary Davidson, and Patricia Snell Herzog. Lost in Transition: The Dark Side of Emerging Adulthood. New York: Oxford University Press, 2011.

33. Dean, Kenda Creasy. Almost Christian: What the Faith of Our Teenagers Is Telling the American Church. New York: Oxford University Press, 2010.

34. Smith, Christian, and Melina Lundquist Denton. Soul Searching: The Religious and Spiritual Lives of American Teenagers. New York: Oxford University Press, 2009.

35. Smith, Tom. "Generation Gaps in Attitudes and Values from the 1970s to the 1990s." In On the Frontier of Adulthood: Theory, Research, and Public Policy. Edited by Richard A. Settersten, Jr., Frank F. Furstenberg and Rubén G. Rumbaut. Chicago: University of Chicago Press, 2005, pp. 177-224.

36. Wuthnow, Robert. After the Baby Boomers: How Twenty-and Thirty-Somethings Are Shaping the Future of American Religion. Princeton: Princeton University Press, 2010.

37. Wuthnow, Robert. America and the Challenges of Religious Diversity. Princeton: Princeton University Press, 2007.

38. Arnett, Jeffrey J. "Emerging Adulthood: What Is It, and What Is It Good For?" Child Development Perspectives 1 (2007): 68-73. [CrossRef]

39. Waters, Mary C., Patrick J. Carr, Maria J. Kefalas, and Jennifer Holdaway, eds. Coming of Age in America: The Transition to Adulthood in the Twenty-First Century. Berkeley: University of California Press, 2011.

40. Hartmann, Douglas, and Teresa Toguchi Swartz. "The New Adulthood? The Transition to Adulthood from the Perspective of Transitioning Young Adults." Advances in Life Course Research, Constructing Adulthood Agency and Subjectivity in Adolescence and Adulthood 11 (2006): 253-86. [CrossRef]

41. Bynner, John. "Rethinking the Youth Phase of the Life-Course: The Case for Emerging Adulthood?" Journal of Youth Studies 8 (2005): 367-84. [CrossRef]

42. Cote, James E. Arrested Adulthood: The Changing Nature of Maturity and Identity. New York: NYU Press, 2000.

43. Osgood, Wayne D., Gretchen Ruth, Jacquelynne S. Eccles, Janis E. Jacobs, and Bonnie L. Barber. "Six Paths to Adulthood: Fast Starters, Parents without Careers, Educated Partners, Educated Singles, Working Singles, and Slow Starters." In On the Frontier of Adulthood: Theory, Research, and Public Policy. Edited by Richard A. Settersten, Frank F. Furstenberg and Rubén G. Rumbaut. Chicago: University of Chicago Press, 2005, pp. 320-55.

44. Cherlin, Andrew J. "The Deinstitutionalization of American Marriage." Journal of Marriage and Family 66 (2004): 848-61. [CrossRef]

45. Domina, Thurston, and Josipa Roksa. "Should Mom Go Back to School? Post-Natal Educational Attainment and Parenting Practices." Social Science Research 41 (2012): 695-708. [CrossRef] [PubMed]

46. Settersten, Richard, and Barbara E. Ray. Not Quite Adults: Why 20-Somethings Are Choosing a Slower Path to Adulthood, and Why It's Good for Everyone. New York: Bantam, 2010.

47. Schwartz, Seth J., Byron L. Zamboanga, Koen Luyckx, Alan Meca, and Rachel A. Ritchie. "Identity in Emerging Adulthood Reviewing the Field and Looking Forward." Emerging Adulthood 1 (2013): 96-113. [CrossRef]

48. Beck, Ulrich. Risk Society: Towards a New Modernity. Thousand Oaks: SAGE, 1992.

49. Fowler, James W. Stages of Faith: The Psychology of Human Development and the Quest for Meaning. San Francisco: HarperOne, 1995.

50. Parker, Stephen. "Research in Fowler's Faith Development Theory: A Review Article." Review of Religious Research 51 (2010): 233-52.

51. Barry, Carolyn McNamara, and Mona M. Abo-Zena, eds. Emerging Adults' Religiousness and Spirituality: Meaning-Making in an Age of Transition. New York: Oxford University Press, 2014.

52. Mayseless, Ofra, and Einat Keren. "Finding a Meaningful Life as a Developmental Task in Emerging Adulthood the Domains of Love and Work across Cultures." Emerging Adulthood 2 (2014): 63-73. [CrossRef]

53. Kimball, Cynthia, Kaye Cook, Chris Boyatzis, and Kathleen Leonard. "Meaning Making in Emerging Adults' Faith Narratives: Identity, Attachment, and Religious Orientation." Journal of Psychology and Christianity 32 (2013): 221-33.

54. Good, Marie, and Teena Willoughby. "Adolescence as a Sensitive Period for Spiritual Development." Child Development Perspectives 2 (2008): 32-37. [CrossRef]

55. Barry, Carolyn McNamara, and Larry J. Nelson. "The Role of Religion in the Transition to Adulthood for Young Emerging Adults." Journal of Youth and Adolescence 34 (2005): 245-55. [CrossRef] 
56. Jung, Jong Hyun. "Sense of Divine Involvement and Sense of Meaning in Life: Religious Tradition as a Contingency." Journal for the Scientific Study of Religion 54 (2015): 119-33. [CrossRef]

57. Barkin, Samuel H., Lisa Miller, and Suniya S. Luthar. "Filling the Void: Spiritual Development among Adolescents of the Affluent." Journal of Religion and Health 54 (2015): 844-61. [CrossRef] [PubMed]

58. Madge, Nicola, Peter Hemming, and Kevin Stenson. Youth on Religion: The Development, Negotiation and Impact of Faith and Non-Faith Identity. New York: Routledge, 2014.

59. Astin, Helen S., and Anthony Lising Antonio. "The Impact of College on Character Development." New Directions for Institutional Research 122 (2004): 55-64. [CrossRef]

60. Weber, James, and David Wasieleski. "Investigating Influences on Managers' Moral Reasoning the Impact of Context and Personal and Organizational Factors." Business \& Society 40 (2014): 79-110. [CrossRef]

61. Godwin, Lindsey N. "Examining the Impact of Moral Imagination on Organizational Decision Making." Business E Society 54 (2015): 254-78. [CrossRef]

62. National Study of Youth and Religion. Available online: http://youthandreligion.nd.edu/ (accessed on 12 June 2015).

(C) 2016 by the authors; licensee MDPI, Basel, Switzerland. This article is an open access article distributed under the terms and conditions of the Creative Commons by Attribution (CC-BY) license (http://creativecommons.org/licenses/by/4.0/). 